\title{
Responses of Two Semiterrestrial Isopods, Ligia exotica and Ligia taiwanensis (Crustacea) to Osmotic Stress
}

\author{
Min-Li Tsai, ${ }^{1,}$ Chang-Feng Dai, ${ }^{2}$ and Hon-Cheng Chen ${ }^{1}$ \\ ${ }^{1}$ Department of Zoology, National Taiwan University, Taipei, Taiwan, ROC; and ${ }^{2}$ Institute of Oceanography, \\ National Taiwan University, Taipei, Taiwan, ROC
}

\begin{abstract}
When immersed in fresh water, Ligia taiwanensis is a poorer osmoregulator than Ligia exotica, as judged by a lower $\mathrm{LD}_{50}$ at $96 \mathrm{hr}$ and by the osmolalities of haemolymph. Animals appear to osmoregulate more efficiently in air. On immersion, both species displayed hyper- and hypo-osmoregulatory ability. Both species subjected less osmotic selection pressure during their inland colonization. The results suggest that a route of terrestrial colonization not involving transitional freshwater stresses had been taken by L. exotica and L. taiwanensis. сомР віоснем PHysiol 118A;1:141-146, 1997. (C) 1997 Elsevier Science Inc.
\end{abstract}

KEY WORDS. Ligia, osmotic stress, terrestrial colonization

\section{INTRODUCTION}

Most extant superfamilies of the order Isopoda are marine, and all terrestrial forms are included in one superfamily, the Oniscidea. Some members of family Ligiidae represent a lesser degree of terrestriality. These species inhabit highlittoral or supralittoral zones where humidity is high, although they require access to water and have been designated "semi-terrestrial" (22); Ligia exotica Roux and Ligia taiwanensis Lee, for example, spend most of the time on land, but must contact with water frequently. Such contacts allow them to cool down and to rehydrate (3).

Only two Ligia species, L. exotica and L. taiwanensis, have been found in Taiwan $(5,11)$. L. exotica is a common species of the supralittoral zone of sheltered and exposed coasts around Taiwan. In contrast, the distribution of L. taiwanensis is limited, and they are only found in the strand of hill streams at Heng Chun Peninsula, southern Taiwan. L. exotica had long been formerly considered a marine species inhabiting the seashore. However, during a field survey, an isolated population of L. exotica was found inhabiting the strand of hill stream about $1 \mathrm{~km}$ away from seashore. It offered an opportunity to study the physiological adaptation of these two semiterrestrial isopods to different environmental conditions (the littoral zone and the strand of a hill stream).

One of the most significant changes associated with a transition between these habitats, from marine to terrestrial, is the change in the osmotic pressure (15). The responses of isopods to this change were important to the

Address reprint requests to: Min-Li Tsai, Department of Zoology, National Taiwan University, Taipei, Taiwan. Tel 3630231-3324.

Received 12 November 1995; accepted 17 October 1996. habitat adaptation. The physiological characteristics of osmoregulation can be used to test some predictions in the physiological evolution $(18,24)$. Water relations, osmoregulation patterns, and environmental tolerances in isopods have been investigated extensively $(1,2,4,13,14,16,19,23$, $26,28,31)$, but it is rare to compare the responses to various osmotic stresses in different acclimation conditions.

In this study, the responses of $L$. taiwanensis and L. exotica to osmolality of media were examined and compared in both aerial exposure and immersion acclimation regimes. The results could provide some clues on the strategies of their terrestrial colonization.

\section{MATERIALS AND METHODS}

Specimens of L. exotica and L. taiwanensis were collected from the strands of hill streams (about $1 \mathrm{~km}$ away from seashore and altitude from 20 to $50 \mathrm{~m}$ ). L. exotica were collected from the littoral rocky shore at Heng-Chen Peninsula. During transportation, animals were maintained in tanks containing the moist substratum from their natural habitat, and covered by a plastic plate to maintain a high humidity. In the laboratory, animals were stored for 2 days in tanks, which were lined with mats of moistened filter paper in the bottom, to allow the osmolality of body fluid to achieve a balance and to clean the guts before the experiments (30). To get sufficiently large haemolymph samples, only the larger animals ( $>15 \mathrm{~mm}$ in body length) were used.

\section{The Responses of the Haemolymph Osmolality to the Osmotic Stress}

Two acclimation regimes were employed, animals were 1) immersed in aerated water, and 2) exposed in air and al- 
lowed free access to water. In the submersed acclimation regimes, 101 of medium of each salinity was added to each tank and aerated. Tanks with smooth walls were used to prevent the animals emerging from the aerated water. In the aerial exposure regime, only about $100 \mathrm{ml}$ of medium was provided.

Twenty to 50 individuals from each of the three populations were sampled randomly from stock animals and placed in each tank. Media were prepared by mixing different amounts of sea water and fresh water, and the osmolalities were measured. A wide range of medium osmolality, from the fresh water to concentrated sea water $(1645 \mathrm{mOsm} / \mathrm{kg})$, was used in this experiment. All data were ultimately expressed as osmolality $(\mathrm{mOsm} / \mathrm{kg})$. Both sea water and fresh water were taken from the sampling sites. The media were aerated throughout the experiment period. Relative humidity $>75 \%$ in an incubation room was maintained at a temperature $25^{\circ} \mathrm{C}$. To achieve steady osmolalities of haemolymph, the animals were acclimated for 1 week. Following acclimation, the haemolymph osmolality of each live individual was measured using a Micro-osmometer $3 \mathrm{MO}$ PLUS, ADVANCED. Haemolymph samples (at least $20 \mu \mathrm{l}$ ) were obtained by puncturing the arthrodial membrane between the second and third dorsal plates using a fine capillary, following the method of Morritt (18).

\section{$\mathrm{LD}_{50}$}

Based on a pre-test, seven medium osmolalities $(104,124$, $143,155,167,196$, and $221 \mathrm{mOsm} / \mathrm{kg}$ ) were used to examine $\mathrm{LD}_{50}$ (the lower medium osmolality which was lethal to $50 \%$ of animals) at $96 \mathrm{hr}$. Among 30 to 50 individuals from three sources were placed in each tank, and immersed in 101 medium. The experiment of each osmolality was executed in triplicate. Mortality rates of isopods were examined at $2-\mathrm{hr}$ intervals on the first day, at 6-hr intervals in the following 3 days, and dead animals were removed immediately. $L_{50}$ was calculated using the program of Trevors and Lusty (27). The same procedure was replicated six times.

\section{The Haemolymph Osmolalities of Dying Animals}

The haemolymph osmolalities of dying animals (in which the beating of pleopods slowed down significantly, and became insensitive to the touch by a probe) immersed in fresh water were also examined as a reference of the tolerance to osmotic stress. Animals (35 individuals) from each population were immersed in fresh water. The individuals were removed and the haemolymph osmolalities of these individuals were measured, as soon as they were dying.

\section{Data Analysis}

The relationships between haemolymph and ambient medium osmolality were described by regression, and a parallel- (a)

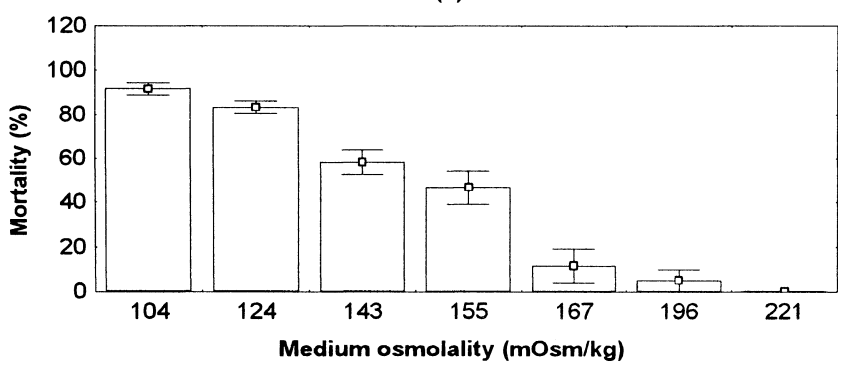

(b)

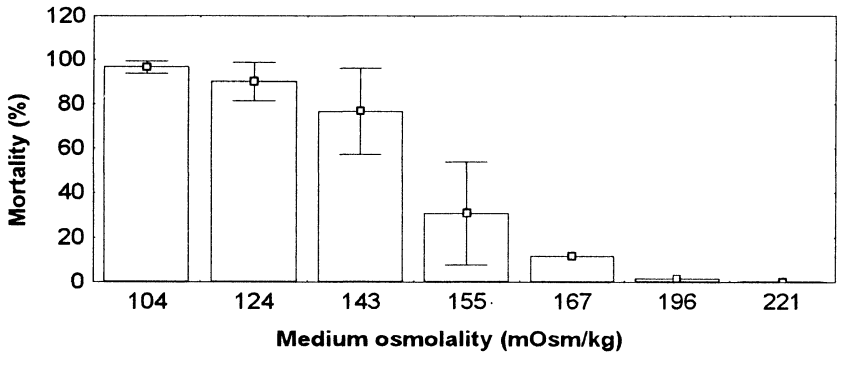

(c)

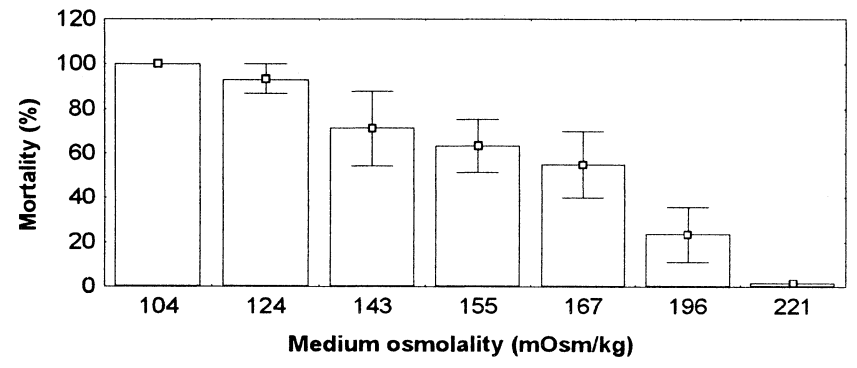

FIG. 1. Mean and standard deviation (mean \pm SD) of percent mortality of isopods immersed for $96 \mathrm{hr}$ in media with different osmolalities $(n=6)$ : (a) littoral Ligia exotica, (b) hill Ligia exotica and (c) hill Ligia taiwanensis.

ism test between the regression equation slopes was carried out by analysis of covariance (ANCOVA). ANOVA and Tukey test (32) were used to test the difference of the $\mathrm{LD}_{50}$ and the haemolymph concentration among the three Ligia populations.

\section{RESULTS}

\section{Mortality and Tolerance}

All individuals exposed in air or immersed in aerated full strength sea water had $100 \%$ survival rates. In contrast, all animals immersed in aerated fresh water died within 4 days. Figure 1 shows the mortality variations of three sources of Ligia when they were immersed in media with different os- 
TABLE 1. Analysis of the tolerance to osmolalities $\left(\mathrm{LD}_{50}\right.$ for $96 \mathrm{hr}$, immersed) and the haemolymph osmolarity of dying animals (immersed in fresh water) among three sources of animals: littoral Ligia exotica, hill Ligia exotica, and Ligia taiwanesis

\begin{tabular}{|c|c|c|c|c|c|c|}
\hline Species and habitats & $\begin{array}{c}\mathrm{LD}_{50} \\
(\mathrm{mOsm} / \mathbf{k g})\end{array}$ & $F$-test & Tukey test & $\begin{array}{c}\text { Haemolymph osmolality } \\
\text { of dying animal } \\
(\mathrm{mOsm} / \mathrm{kg})\end{array}$ & $F$-test & Tukey test \\
\hline $\begin{array}{l}\text { Ligia exotica } \\
\text { Marine (littoral) }\end{array}$ & $\begin{array}{c}149 \pm 9 \\
(n=6)\end{array}$ & & a & $\begin{array}{l}559 \pm 35 \\
(n=35)\end{array}$ & & a \\
\hline $\begin{array}{l}\text { Ligia exotica } \\
\text { Stream (strand) }\end{array}$ & $\begin{array}{c}146 \pm 26 \\
(n=6)\end{array}$ & $p<.01$ & $\mathrm{a}$ & $\begin{array}{l}560 \pm 27 \\
(n=35)\end{array}$ & $p<.001$ & a \\
\hline Ligia taiwanensis & $170 \pm 16$ & & b & $614 \pm 23$ & & $\mathrm{~b}$ \\
\hline Stream (strand) & $(n=6)$ & & $p<.001$ & $(n=35)$ & & $p<.001$ \\
\hline
\end{tabular}

$\mathrm{a}, \mathrm{b}$ are significantly by Tukey test, $p<0.001$.

molalities. In the immersion experiments, the lower lethal osmolalities for $50 \%$ of the animals were $140 \pm 9 \mathrm{mOsm} /$ $\mathrm{kg}$ for littoral L. exotica, $146 \pm 26 \mathrm{mOsm} / \mathrm{kg}$ for hill $\mathrm{L}$. exotica, and $170 \pm 16 \mathrm{mOsm} / \mathrm{kg}$ for $L$. taiwanensis. The $\mathrm{LD}_{50}$ for $L$. taiwanensis was significantly higher than that of $L$. exotica; no significant difference was found between two populations of L. exotica (Table 1 ).

Although L. taiwanensis was only found at hill stream far from the seashore, the ability to tolerate low external osmotic pressure was slightly reduced, compared with that of littoral or of strand L. exotica. To confirm this, the characterization of capacity to tolerate the lower haemolymph osmolality was estimated by examining the haemolymph osmolality of dying individuals, which were immersed in fresh water. The average haemolymph osmolalities of dying animals were $559 \pm 35,560 \pm 27$, and $614 \pm 23 \mathrm{mOsm} / \mathrm{kg}$ for littoral L. exotica, hill stream L. exotica, and L. taiwanensis, respectively. The result corresponded to the $\mathrm{LD}_{50}$ (Table 1 ).

\section{Relationship Between Haemolymph and Medium Osmolality}

A simple linear regression model was used to show the relationships between internal and external osmolalities. The equations are given in Figs 2 and 3. All three populations showed significant differences in slopes between two acclimation regimes $(p<0.001$ for littoral L. exotica; $p<0.001$ for hill $L$. exotica, $p<0.001$ for hill $L$. taiwanensis, ANCOVA). In the aerial exposure regime, the three populations showed a common slope $(p>0.5, \mathrm{NS})$. In immersed regimes, the slopes were different $(p<0.01)$ between the species; there was no difference between the two populations of L. exotica $(p>0.5, \mathrm{NS})$.

Upon immersion, all three populations displayed both hyper- and hypo-osmoregulatory abilities. The ability of osmoregulation seemed to be better in lower salinity media than that of in higher salinity media (osmolality levels above $1300 \mathrm{mOms} / \mathrm{kg}$ ) (Fig. 2). In the exposed regimes, the haemolymph concentrations were less affected by media, compared to those immersed (Figs 2 and 3). The osmoregu- latory patterns of both species were similar, yet the ranges tolerated were different.

\section{DISCUSSION}

\section{Lethal Effect of Immersion}

The retention of exosomatic water (such as the water existing in the body grooves, between the pleopods, and in the capillary uropods) was a key to success of many semiterrestrial amphipods and isopods (including the supralittoral Ligia) invading land, and this exosomatic water allows "aquatic" methods of gas, water, and ion exchange $(8,10,24,25)$. As such, it is not surprising that $L$. exotica and L. taiwanensis can survive when immersed in aerated sea water. A terrestrial isopod, Armadillidium album Dollfuss, also showed to be very tolerant toward immersion in sea water (28). Similar results were also found in some littoral

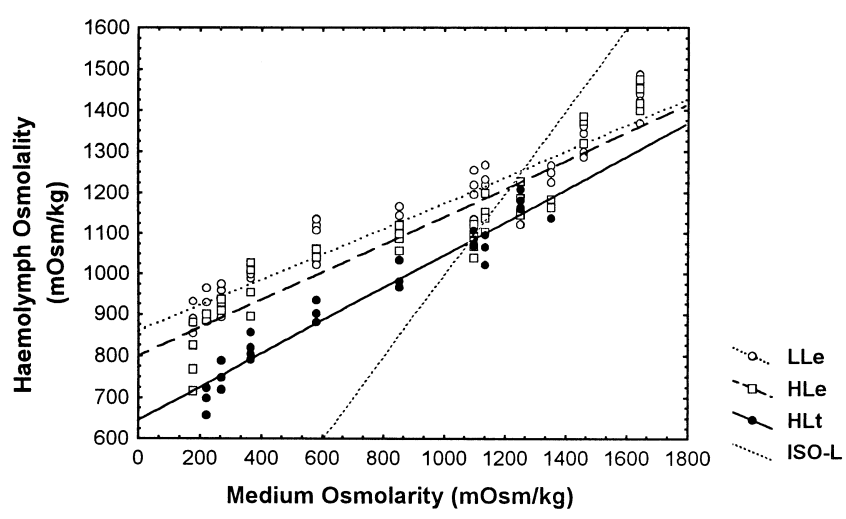

FIG. 2. Graphs plotting haemolymph osmolality against external osmolality for the littoral Ligia exotica (LLe); hill $L$. exotica (HLe); hill L. taiwanensis (HLt) in the submersion acclimation regimes, and iso-osmotic line (ISO-L). The equations of linear regression are: LLe $Y=859.8+0.3 \mathrm{X}(n$ $=44 ; F=374.5 ; R=.948 ; P<.001 ; t_{\text {intercept }}=54.7 ; \mathrm{t}_{\text {slope }}=$ 19.3), SLe $Y=803.8+0.3 \mathrm{X}(n=44 ; F=303.1 ; R=.937$; $\left.P<.001 ; \mathrm{t}_{\text {intercept }}=43.4 ; \mathrm{t}_{\text {slope }}=17.4\right) ; \mathrm{Lt} Y=671.0+0.4 \mathrm{X}$ $\left(n=36 ; F=272.7 ; R=.949 ; P<.001 ; t_{\text {intercept }}=32.1 ; t_{\text {slope }}\right.$ $=16.5$ ). 


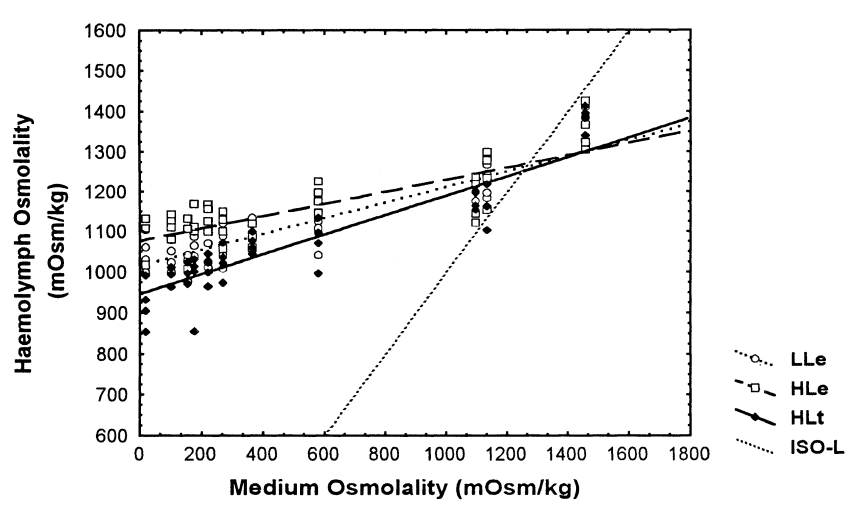

FIG. 3. Graphs plotting haemolymph osmolality against external osmolality for the littoral Ligia exotica (LLe); hill $L$. exotica (HLe); hill $L$. taiwanensis (HLt) in the aerial exposure acclimation regimes, and iso-osmotic line (ISO-L). The equations of linear regression are: LLe $Y=1015.6+0.2 \mathrm{X}$ $\left(n=44 ; F=183.0 ; R=.902 ; P<.001 ; t_{\text {intercept }}=101.1 ; t_{\text {slope }}\right.$ $=13.5)$; SLe $Y=1077.6+0.2 \mathrm{X}(n=44 ; F=82.154 ; R=$ $\left..813 ; P<.001 ; \mathrm{t}_{\text {intercept }}=91.8 ; \mathrm{t}_{\text {slope }}=9.1\right) ; \mathrm{Lt} Y=946.8+$ $0.2 X\left(n=44 ; F=176.6 ; R=.899 ; P<.001 ; t_{\text {intercept }}=74.7\right.$; $\left.\mathrm{t}_{\text {slope }}=13.1\right)$.

and terrestrial amphipods (18). Another field observation found that Ligia italica had to emerge from an intertidal pool at intervals to breathe in air (7). This emergence of $L$. italica may be related to the insufficient dissolved oxygen in an intertidal pool. In our experiments, aeration was very important for the survival of animals immersed in water. Morritt (18) found that the mortalities of some littoral and terrestrial talitroidean amphipods were increased in nonaerated water (18). In this study, none of the isopods could survive when they were immersed in water without aeration.

Animals immersed in freshwater were all dead within 96 $\mathrm{hr}$, yet those immersed in sea water all survived under the same aerated condition. It seems likely that this immersion in aerated water itself did not have any lethal effect. Therefore, the reduction of survival rate is not likely to be related to the inability to maintain a sufficiently high rate of oxygen consumption under conditions of immersion. Accordingly, the change of osmotic pressure in the medium may be the main factor that affected the survival of the animals.

\section{Tolerance to Osmotic Stresses}

None of the animals could withstand the osmotic stress in fresh water, although they showed a wide range in salinity tolerance. The similar range of salinity tolerance was also observed in the euryhaline isopod Sphaeroma serratum (4). Osmoregulatory ability of $L$. taiwanensis immersed in fresh water was lower than that of L. exotica, as demonstrated by the $\mathrm{LD}_{50}$ at $96 \mathrm{hr}$ and based on the haemolymph osmolalities (Table 1).

It is interesting that the individuals of $L$. taiwanensis, only inhabiting hill streams, were less tolerant to osmotic stress of fresh water compared to littoral L. exotica when immersed (Table 1). In this case, this lesser tolerance to fresh water of L. taiwanensis, seems unlikely to have evolved secondarily. It is unfavorable for $L$. taiwanensis inhabiting hill streams to maintain haemolymph concentration at such a high level. However, metabolic cost of osmoregulation is substantial (20). The most probable explanation is that this inability to tolerate low osmolality of fresh water and the high level of haemolymph osmolality, are traits of their marine ancestors.

\section{Comparison of Haemolymph Osmolality}

Barnes (1) had emphasized the wide variation in osmotic pressure of blood found in crustaceans. Little (15) suggested that many terrestrial invertebrates with a relatively high osmotic pressure probably have a direct marine origin, while those with a low osmotic pressure and little tolerance of internal change were probably descended from freshwater ancestors. Comparing the blood osmolality with the other isopods $(16,19)$, the haemolymph osmolality of L. taiwanensis is much higher than that of true freshwater species, Ligia aquaticus (L), and closer to those of littoral species, Ligia oceanica (L.) and L. exotica, and a terrestrial species with a presumed marine origin, Porcellio scaber (13) (Table 2). Similar phenomena have been reported for freshwater crabs (29). These authors noted that "Although the blood osmoconcentration in freshwater crabs is significantly above that of the ambient fluid, it is less than that of marine crabs."

The haemolymph osmolality of hill L. exotica is only slightly lower than that of seashore L. exotica (Table 2). It seems likely that $L$. exotica subjected less osmotic selection pressure during their inland colonization. This result supports the remarks by Potts (21). "Once on land, the blood concentration is no longer subject to strong selection". This presumption of the marine origin, might also provide a good

TABLE 2. Comparison of the haemolymph osmotic pressure in some isopods residing in different habitats

\begin{tabular}{|c|c|c|}
\hline Species & Natural habitat & $\begin{array}{c}\text { Blood } \\
\text { osmolality } \\
(\mathrm{mOsm} / \mathrm{kg})\end{array}$ \\
\hline Asellus acquaticus & Freshwater (aquatic) & $120^{\mathrm{a}}$ \\
\hline Porcellio scaber & Moist substrate (terrestrial) & $700^{b}$ \\
\hline Ligia oceanica & Sea water (littoral) & $1160^{c}$ \\
\hline Ligia exotica & Sea water (littoral) & $1185 \pm 32^{\mathrm{d}}$ \\
\hline Ligia exotica & Freshwater (hill) & $1095 \pm 53^{\mathrm{d}}$ \\
\hline Ligia taiwanensis & Freshwater (hill) & $921 \pm 57^{d}$ \\
\hline
\end{tabular}


explanation for the high haemolymph osmolality of L. taiwanensis.

\section{Osmoregulation}

In order to compare the relationships between medium and haemolymph osmolalities of three populations easily, a regression model was used. A second-order polynomial regression model had been used previously to describe the relationships between haemolymph and medium osmolality of amphipods (18). In this study, the estimates of regression coefficient of second-order term were not significant. Therefore, a simple linear regression model was used.

All three populations show different slopes between different acclimation regimes. Price and Holdich also found differences in osmoregulatory ability of L. oceanica during aerial desiccation and immersion (23). In aerial exposure regimes, the haemolymph osmolality of animals (both species) was less affected by the ambient medium compared to that of immersion. It seems that the animals osmoregulated more efficiently in the air.

Although the ability to regulate hypoosmotically was weaker compared to that of hyper-osmoregulation, when immersed both species demonstrated both hyper- and hypoosmoregulatory abilities (Fig. 2). The ability for hypoosmoregulation has been regarded as a possible pre-adaptation to terrestrial life $(6,17)$, and has been demonstrated in Ligia occidentalis and L. pallasii (31). Some littoral and supralittoral Ligia species maintain relatively high internal concentrations, even in low salinity media $(19,26,31)$, and can also osmoregulate at high salinity $(2,12)$. Although the ability of osmoregulation might be an advantage for L. exotica and L. taiwanensis to resist the extreme osmotic stresses, it might be too expensive energetically for long-term survival in such an extreme environment (20).

\section{Land Colonization}

Bliss and Mantel (3) suggested that certain species, though closely related, may have approached land via different routes: across sandy beaches or the rocky intertidal zone, through mangrove swamps, or by way of freshwater lakes and streams. Several possible scenarios might be suggested for L. taiwanensis and L. exotica to colonize in the strand of hill brooks.

The osmotic pressure of haemolymph may reflect the ancestral type of terrestrial isopods because the blood concentration might subject less selected pressure and maintained at the previous levels once on land (21). Little (15) suggested that blood osmolality is probably the most widely available physiological character reflecting the ancestry of animals. The results of our physiological study on osmoregulation presume that $L$. taiwanensis and L. exotica took route of terrestrial invasion not involving great transitional freshwater stresses. The similar result that Ligiidae were derived from marine ancestors, was also suggested by Edney (9) based on morphological characteristics.

\section{References}

1. Barnes, R.S.K. Individual variation in osmotic pressure of an ocypodid crab. Comp. Biochem. Physiol. 27:447-50;1968.

2. Bayly, I.A.E.; Ellis, P. Haloniscus searlei Chlton: An aquatic "terrestrial" isopod with remarkable powers of osmotic regulation. Comp. Biochem. Physiol. 31:523-528;1969.

3. Bliss, D.E.; Mantel, L.H. Adaptations of crustaceans to land: A summary and analysis of new findings. Am. Zool. 8:545$559 ; 1968$.

4. Charmantier, G.; Charmantier, D.M. Ontogeny of osmoregulation and salinity tolerance in the isopod crustacean Sphaeroma serratum. Mar. Ecol. Pro. Ser. 114:93-101;1994.

5. Chen, G.X. The descriptions of two sea-slaters from China. Chinese J. Zool. 22:8-11;1987.

6. Dall, W. Hypo-osmoregulation in crustacea. Comp. Biochem. Physiol. 21:653-678;1967.

7. Davenport, J. Observations on the behaviour, salinity relations and colour change of Ligia italica from Madeira. J. Mar. Biol. Assoc. U. K. 74:959-962;1994.

8. Edney, E.B. Terrestrial adaptations. In: Waterman, T.H. (ed). The Physiology of Crustacea. 1. New York: Academic Press; 1960:367-393.

9. Edney, E.B. Transition from water to land in isopod crustaceans. Am. Zool. 8:309-326;1968.

10. Hoese, B. The marsupium in terrestrial isopods. Symp. Zool. Soc. Lond. 53:65-76;1984.

11. Lee, J.D. A new mountain slater, Ligia taiwanensis (Isopoda, Ligiidae) from Taiwan. Crustaceana 66:110-115;1994.

12. Lindquist, O.V.; Fitzgerald, G. Osmotic interrelationship between blood and gut fluid in the isopod Porcellio scaber (Crustacea). Comp. Biochem. Physiol. 53A:57-59;1976.

13. Little, C. The colonization of land. Origins and adaptations of terrestrial animals. New York: Cambridge University Press; 1983.

14. Little, C. Comparative physiology as a tool for investigating the evolutionary routes of animals on to land. Trans. R. Soc. Edinb. Earth Sci. 80:201-208;1989.

15. Little, C. The terrestrial invasion: An ecophysiological approach to the origins of land animals. New York: Cambridge University Press; 1990.

16. Lockwood, A.P.M. Some effects of temperature and concentration of the medium on the ionic regulation of isopod Asellus aquaticus (L.). J. Exp. Biol. 36:546-554;1960.

17. Mantel, L.H.; Farmer, L.L. Osmotic and ionic regulation. In: Mantel, L.H. (ed). The Biology of Crustacea, Vol. 5. New York: Academic Press; 1983.

18. Morritt, D. Osmoregulation in littoral and terrestrial talitroidean amphipods (Crustacea) from Britain. J. Exp. Mar. Biol. Ecol. 123:77-94;1988.

19. Parry, G. Osmotic and ionic regulation in the isopod crustacean Ligia oceanica (L.). J. Exp. Biol. 30:567-574;1953.

20. Potts, W.T.W. The energetics of osmoregulation in brackishand freshwater animals. J. Exp. Biol. 31:618-630;1954.

21. Potts, W.T.W. Discussion after "The evolution of terrestrial vertebrates: Environmental and physiological considerations" by AA Bray. Phil. Trans. R. Soc. Lond. B 309:319-320;1985.

22. Power, L.W.; Bliss D.E. Terrestrial adaptation. In: Vernberg, F.J.; Vernberg, W.B. (eds.) The Biology of Crustacea, Vol. 8. New York: London Academic Press; 1983.

23. Price, J.B.; Holdich, D.M. Changes in osmotic pressure and sodium concentration of haemolymph of woodlice with pro- 
gressive desiccation. Comp. Biochem. Physiol. 66A:297-305; 1980.

24. Spicer, J.I.; Taylor A.C. The origin and metabolic significance of exosomatic water in the semi-terrestrial beachflea, Orchestia gammarellus (crustacea: Amphipoda). J. Zool. 232(4):617632;1994.

25. Spicer, J.I.; Moore, P.G.; Taylor, A.C. The physiological ecology of land invasion by the Talitridae (Crustacea: Amphipoda). Proc. R. Soc. Lond. Ser. B 232:95-124;1987.

26. Todd, M.E. Osmoregulation in Ligia oceanica and Idotea granulosa. J. Exp. Biol. 40:381-392;1963.

27. Trevors, J.T.; Lusty, C.W. A basic microcomputer program for calculated $L_{D 50}$ values, water air and soil. Pollution 24:431$442 ; 1985$.
28. Vander, W.; DeWolf, L. Biotope and biology of Armadilldium album Dollfuss, a terrestrial isopod of sandy beaches, in southwestern Netherlands. Netherlands J. Sea. Res. 22:175-184; 1988.

29. Vernberg, W.B.; Vernberg, F.J. Freshwater adaptations. In: Vernberg, F.J.; Vernberg, W.B. (eds). The Biology of Crustacea, Vol. 8. New York: Academic Press; 1983.

30. Willow, R.I. Population and individual energetics of Ligia oceanica (L.) (Crustacea: Isopoda) in the rocky supralittoral. J. Exp. Mar. Biol. Ecol. 105:253-274;1987.

31. Wilson, W.J. Osmoregulatory capabilities in isopods: Ligia occidentalis and Ligia pallasii. Biol. Bull. 138:96-108;1970.

32. Zar, J.H. Biostatistical Analysis. 2nd Ed. Englewood Cliffs, NJ: Prentice-Hall; 1984. 